\title{
Perancangan Sistem Informasi Jadwal Dokter Menggunakan Framework Codeigniter
}

\author{
Achmad Fikri Sallaby ${ }^{1}$, Indra Kanedi ${ }^{2}$ \\ 1Dosen Tetap Program Studi Sistem Informasi Fakultas Ilmu Komputer Universitas Dehasen Bengkulu Jl. Meranti \\ Raya No. 32 Kota Bengkulu 38228 Telp. (0736) 22027, 26957 Fax. (0736) 341139) \\ Jl. e-mail: fikrisallaby@unived.ac.id, indrakanedi12@,gmail.com²
}

\begin{abstract}
One form of teaching materials interactive is module interactive. Interactive module is a unified learning, setting designed to help students individually in achieving the purposes of study. This study aims to develop interactive module on the subjects of integrated IPA class VIII. The research method used is research development with stages of designing, production, evaluation, and analyzing data by percentage. The results of this study indicate that media is learning to interactive module developed on the subjects of integrated IPA class VIII is feasible for use in learning by teachers and students. Based on several stages of trial, the learning media is categorized valid with the level of feasibility of $82 \%$ with good criteria. This research is expected to be a medium of learning on the subjects of integrated IPA class VIII and can be useful for teachers, students, and advanced researchers.
\end{abstract}

Keywords: Interactive Module, Learning Media, Development, IPA

Intisari- Rumah Sakit dan Puskesmas ataupun klinik merupakan suatu institusi yang bergerak di bidang pelayanan kesehatan masyarakat. Sangat penting bagi Rumah sakit, Puskesmas dan Klinik untuk menampilkan Jadwal Dokter. Hal ini dilakukan agar pasien mengetahui Jadwal Praktek Dokter pada saat itu yang lebih akurat. Sistem Informasi merupakan kumpulan dari data satu kesatuan yang diinformasikan dengan baik dan benar dan juga informasi yang disampaikan bisa diterima dengan baik. Metode pengembangan sistem yang digunakan adalah dengan model waterfall (Air Terjun). Analisis perancangan meliputi Use Case Diagram, Activity Diagram, Class Diagram, dan Sequence Diagram. Implemeentasi menggunakan alat seperti Framework Codeigniter sebagai desain tampilan antarmuka dan MySQL sebagai pengolahan

database.

Kata Kunci : Rumah Sakit, Puskesmas, Klinik, Sistem Informasi, Waterfall, Use Case Diagram, Activity Diagarm, Class Diagram, Sequence Diagram Framework Codeigniter dan MySQL.

\section{PENDAHULUAN}

Faktor kesehatan merupakan salah satu faktor yang penting dalam kehidupan masyarakat terutama untuk mendapatkan layanan kesehatan ketika sakit atau membutuhkan pelayanan kesehatan seperti hanya sekedar konsultasi. Salah satu layanan tersebut adalah jadwal dokter. Dengan adanya jadwal dokter pasien bisa mengetahui dengan akurat jadwal dokter yang tersedia pada saat itu. sistem informasi merupakan kumpulan data dalam satu kesatuan yang bermanfaat disampaikan dengan baik dan benar sehingga penerima bisa menerima informasi dengan baik dan benar informasi tersebut. Dengan menerapkan sistem informasi pasien dapat dengan mudah mendapatkan informasi mengenai jadwal dokter secara akurat.

CodeIgniter merupakan framework PHP yang dibuat berdasarkan model view Controlleer (MVC). CI memiliki library yang lengkap untuk mengerjakan operasi-operasi yang umum dibutuhkan oleh aplikasi berbasis web misalnya mengakses database, memvalidasi form sehingga sistem yang dikembangkan mudah. CI juga menjadi satu-satunya Framework dengan dokumentasi yang lengkap dan jelas. Source code CI yang dilengkapi dengan comment didalamnya sehingga lebih memperjelas fungsi sebuah kode program dan CI yang dihasilkan sangat Bersih (clean) dan search Engine Friendly (SEF). Codeigniter juga dapat memudahkan developer dalam membuat aplikasi web berbasis PHP, karena framework sudah memiliki kerangka kerja sehingga tidak perlu menulis semua kode program dari awal. Selain itu, struktur dan susunan logis dari codeigniter membuat aplikasi menjadi semakin teratur dan dapat fokus pada fitur-fitur apa yang akan dibutuhkan dalam pembuatan aplikasi tersebut. (Awan Pribadi Basuki:2010)

Dengan menggunakan framework codeigniter ini diharapkan dapat memberikan layanan informasi jadwal praktek dokter secara optimal. Sehingga pasien tidak perlu datang fasilitas kesehatan apabila hanya ingin melihat jadwal dokter free untuk konsultasi. 
Berdasarkan uraian diatas, maka penulis tertarik untuk melakukan penelitian dengan judul: "Perancangan Sistem Informasi Jadwal Dokter Menggunakan Framework Codeigniter".

\section{TINJAUAN PUSTAKA}

A. Sistem

Sistem menurut suatu jaringan kerja dari prosedur-prosedur yang saling berhubungan, berkumpul bersama-sama untuk melakukan suatu kegiatan atau untuk menyelesaikan suatu sasaran yang tertentu [1]. Sistem adalah Serangkaian data atau lebih komponen yang saling terkait dan berinteraksi untuk mencapai tujuan [2]. Sistem adalah merupakan satu kesatuan data yang terhubung dan teroganisir secara prosedural.

\section{B. Informasi}

Informasi adalah data yang telah dikelola dan diproses untuk memberika arti dan memperbaiki proses pengambilan keputusan [3]. informasi adalah data yang telah diproses dengan suatu cara untuk memberikan arti dan memperbaiki pengambilan keputusan[4]. Berdasarkan uraian di atas maka penulis mengambil keputusan bahwa informasi adalah sekumpulan data yang diproses sehingga menghasilkan informasi yang bermanfaat dan informasi tersebut dapat diterima dengan baik oleh penerima informasi.

C. Sistem Informasi

Sistem informasi adalah suatu sistem di dalam suatu organisasi yang mempertemukan kebutuhan pengolahan transaksi harian yang mendukung fungsi organisasi yang bersifat manajerial dalam kegiatan strategi dari suatu organisasi untuk dapat menyediakan kepada pihak luar tertentu dengan laporan-laporan yang diperlukan oleh pihak luar tertentu[5]. Sistem Informasi dapat didefinisikan sebagai suatu sistem di dalam suatu organisasi yang merupakan kombinasi dari orang, fasilitas, teknologi, media, prosedur dan pengendalian yang ditujukan untuk mendapatkan jalur komunikasi penting, memproses tipe transaksi rutin tertentu, memberi sinyal kepada manajemen dan yang lainnya terhadap kejadian internal dan eksternal yang penting dan menyediakan suatu dasar informasi untuk pengembalian keputusan yang cerdik [6].

Disini penulis menyimpulkan jika Sistem Informasi adalah suatu sistem yang yang terorganisir yang berfungsi untuk mengolah informasi yang bermanfaat yag mempunyai tujuan tertentu dan informasi yang akan disampaikan dapat diterima dengan baik oleh penerima sehingga tujuan tersebut dapat tercapai.

\section{Pengertian Jadwal}

Penjadwalan adalah : "pengaturan waktu dari suatu kegiatan operasi penjadwalan mencakup kegiatan mengalokasikan fasilitas, peralatan ataupun tenaga kerja bagi suatuoperasi. Dalam hierarki pengambilan keputusan,penjadwalan merupakan langkah terakhir sebelum

[7]. Jadwal merupakan suatu informasi yang menunjukkan suatu rencana kegiatan atau pekerjaan yang akan dilakukan, pelaksana kegiatan atau pekerjaan, waktu kegiatan atau pekerjaan yang bertujuan agar kegiatan atau pekerjaan tersebut lebih terorganisir dan sesuai dengan rencana.

E. Metode Pengembangan Sistem

Perancangan suatu sistem informasi berdasarkan rekayasa informasi adalah satu sumber dari proyek pengembangan basis data. Beberapa proyek melakukan pengembangan basis data atau sistem informasi guna memenuhi kebutuhan strategis organisasi. Salah satu metode model pengembangan sistem adalah dengan menggunakan model waterfall yaitu proses perencanaan yang dilakukan dan langkah apa saja yang harus dilakukan serta setiap proses langkah pengembangan sistem harus dilakukan secara berurutan setiap langkahnya. Adapun langkah langkah model pengembangan sistem waterfall adalah sebagai berikut :

1. Analisa sistem

Tahapan ini merupakan tahapan dimana dilakukan proses analisa setiap kebutuhan user yang akan menggunakan aplikasi. dari tujuan pengembangan sistem, siapa pengguna sistem, jadwal pekerjaan.

2. Sistem dan software sistem 
Tahapan ini merupakan tahapan dimana dilakukan desain sistem seperti menentukan hardware, software yang akan digunakan dengan membentuk sistem secara keseluruhan.

3. Implementasi dan unit testing

Ditahapan ini dilakukan pengujian dimana desain perangkat lunak yang telah dirancang dapat memenuhi kebutuhan dan sesuai dengan spesifikasi yang telah ditentukan.

4. Integrasi dan sistem testing

Program diintegrasikan dan diuji sebagai sistem yang lengkap dan kembali memastikan perangkat lunak yang telah diuji benar benar sesuai dengan spesifikasi yang telah ditentukan

5. Operasi dan meintenance

Tahapan akhir dari pengembangan sistem. Pada tahapan ini dilakukan proses instalasi perangkat lunak dan dilakukan maintenace.

F. Pengertian Framework

Framework adalah kumpulan intruksi-intruksi yang dikumpulkan dalam class dan function-function dengan fungsi masing-masing untuk memudahkan developer dalam

memanggilnya tanpa harus menuliskan syntax program yang sama berulang-ulang serta dapat menghemat waktu[8].

G. Pengertian Codeigniter

CodeIgniter adalah Sebuah framework php yang bersifat open source dan menggunakan metode MVC (Model, View, Controller) untuk memudahkan developer atau programmer dalam membangun sebuah aplikasi berbasis web tanpa harus membuatnya dari awal [9].

\section{III.METODE PENELITIAN}

\section{A. Metode Penelitian}

Dalam pengembagan sistem informasi ini menggunakan metode pengembangan sistem model waterfall dengan tahapan sebagai berikut :

1. Analisa sistem

Dilakukan analisa kebutuhan sistem dengan melakukan pengamatan langsung kesetiap faskes dan
Rumah Sakit dan melakukan wawancara keseluruh user disetiap faskes

2. Sistem dan software sistem

Mengamati sistem yang sudah berjalan, kemudian membuat perencanaan dengan mendesain sistem tersebut.

3. Implementasi dan unit testing

Menerapkan desain sistem tersebut kedalam program kemudian dilakukan test untuk melihat apakah sistem yang telah dibuat sesuai dengan kebutuhan atau tidak

4. Integrasi dan sistem testing

Melakukan integrasi sistem yang telah dirancangan dan kembali dites untuk melihat sistem yang telah dikembangkan telah sesuai dengan kebutuhan.

B. Perangkat Lunak

Untuk mendukung penelitian ini perangkat yang digunakan peneliti adalah 1 unit laptop dengan spesifikasi :

1. Sistem operasi windows 10

2. Mozilla

Adapun bahasa pemorograman yang digunakan adalah PHP dan MySQL

C. Metode pengumpulan data.

Untuk mendapatkan data peneliti menggunakan beberapa metode yaitu :

1. Metode Observasi

Merupakan metode dimana peneliti melakukan pengamatan langsung setiap faskes dan Rumah Sakit

2. Metode studi pustaka

Merupakan metode pengumpulan data yang dilakukan dengan cara membaca buku-buku yang berhubungan dengan masalah yang dibahas dalam penelitian ini

3. Metode wawancara

Merupakan metode dimana peneliti melakukan wawancara langsung terhadap user disetiap faskes dan Rumah Sakit.

D. Metode perancangan sistem

1. Analisa sistem aktual 
Sistem penjadwalan dokter pada umumnya dilakukan dengan membuat baliho ataupun spanduk. Sistem ini mempunyai kendala dimana calon pasien atau calon keluarga pasien harus mendatangi secara langsung faskes yang akan dikunjungi sehingga pelayanan tidak berjalan secara optimal. Berdasarkan pada hasil pengamatan diatas maka sistem yang sudah ada pada umunya kurang efektif dan efisien, maka melalui penelitian ini peneliti merancangan sistem informasi jadwal dokter sehingga calon pasien ataupun calon keluarga pasien tidak perlu lagi harus mendatangi faskes yang akan dikunjungi.

2. Analisa sistem baru

Pada sistem baru ini akan dirancang sistem informasi pencarian penelitian dengan menggunakan sistem komputerisasi, dengan komputerisasi memungkinkan pemberian informasi dan pengolahan data yang lebih cepat dan mudah dalam pencarian data yang diinginkan sewaktu-waktu. Sistem informasi pencarian judul ini menggunakan pemrograman PHP MySQL

\section{Rancangan Pengujian}

Pengujian adalah proses eksekusi suatu program dengan maksud menemukan kesalahan Rancangan pengujian yang dilakukan menggunakan metode berikut ini

a) Pengujian Offline, dilakukan secara offline menggunakan server local (localhost). Untuk melakukan pengujian local digunakan software WAMP Server dan Web Broser, Pengujian offline akan melihat hasil website sebelum di upload ke web server online. Pada pengujian offline akan terlihat hasil tampilan dari masing-masing menu.

b) Pengujian Online, dilakukan setelah pengujian secara offline di komputer localhost tidak mengalami masalah. Setelah seluruh data di upload ke web server, dilakukan pengujian dengan mengetikkan alamat

c) Pengujian Alpha, dilakukan dengan menggunakan metode black box. Untuk pengujian alpha ini yaitu pada pengujian sebagai pengguna. Beberapa hal yang diuji pada pengujian ini adalah pengujian login, pengujian pengolahan data (penambahan data, pengeditan data dan penghapusan data) dan pengujian hasil pengolahan data dapat ditampilkan sesuai dengan output yang diharapkan.

\section{IV.HASIL DAN PEMBAHASAN}

Aplikasi ini berhasil dibangun sesuai dengan kebutuhan yang diperlukan oleh sistem, sehingga aplikasi ini diharapkan mampu menunjang dan membantu pihak yang terkait dalam proses pengolahan data dan menghasilkan informasi yang cepat, efektif akurat dan efisien.

\section{A. Tampilan Menu Utama}

Pada tampilan ini digunakan untuk user melihat jadwal dokter, berita yang tersedia dan artikel yang ada di sistem. Untuk admin juga harus tetap melalui menu utama dengan memilih menu admin. Tampilan menu utama dapat dilihat pada gambar 1.

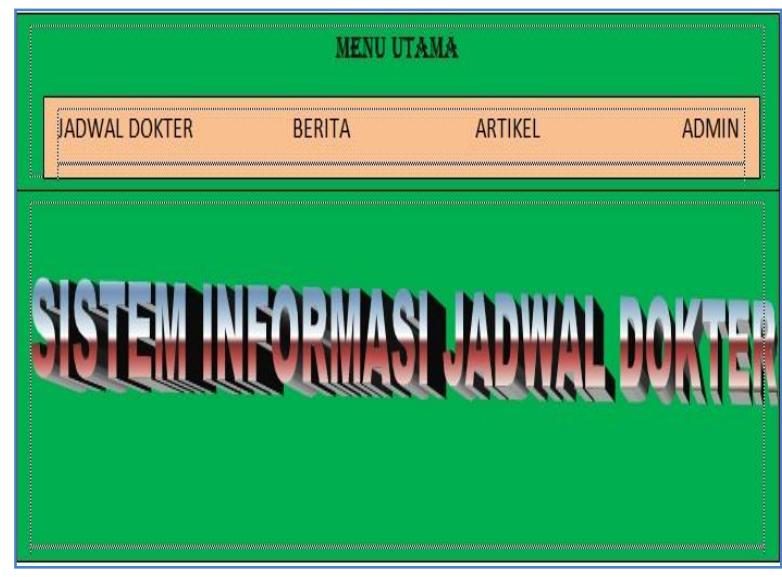

Gambar 1. Tampilan Menu Utama

\section{B. Tampilan Jadwal Dokter}

Untuk melihat jadwal dokter user tinggal memilih dengan cara klik jadwal dokter yang ada ditampilan menu utama. 


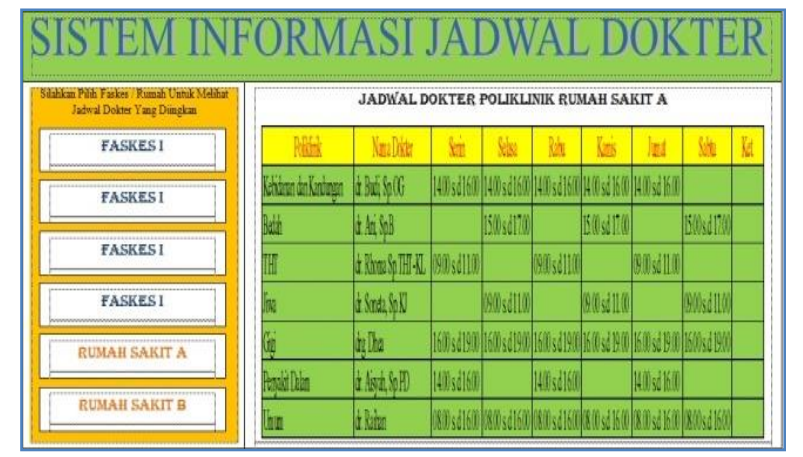

Gambar 2. Tampilan Jadwal Dokter

\section{Tampilan Menu Berita}

Tampilan menu berita merupakan tampilan berita yang terbaru yang ada faskes dan Rumah Sakit. Adapun tampilan Menu Berita dapat dilihat pada gambar 3.

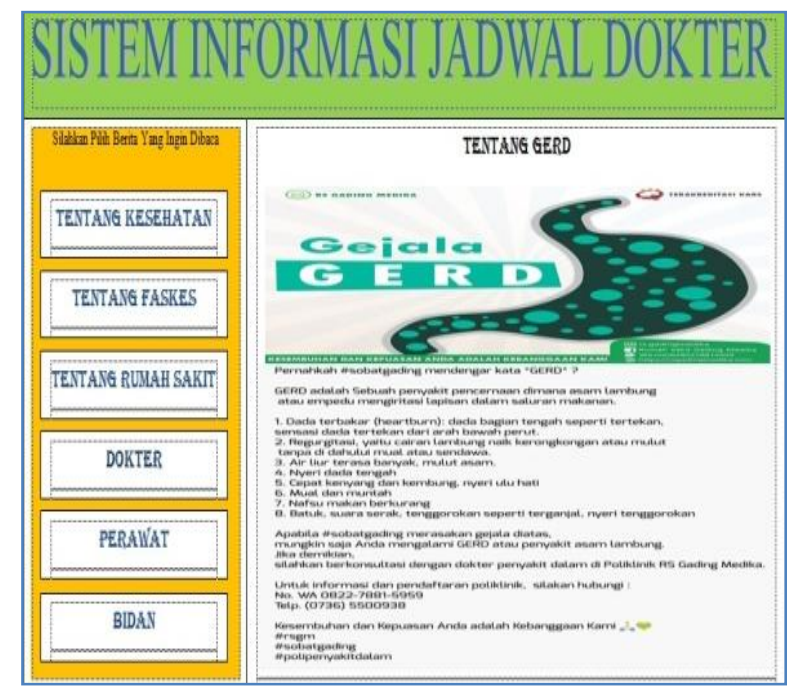

Gambar 3. Tampilan Menu Berita.

\section{Tampilan Menu Login Admin}

Tampilan ini merupakan tampilan filter dari seorang admin ketika ingin masuk kedalam menu admin pada sistem ini. Menu login dapat dilihat pada gambar 4.

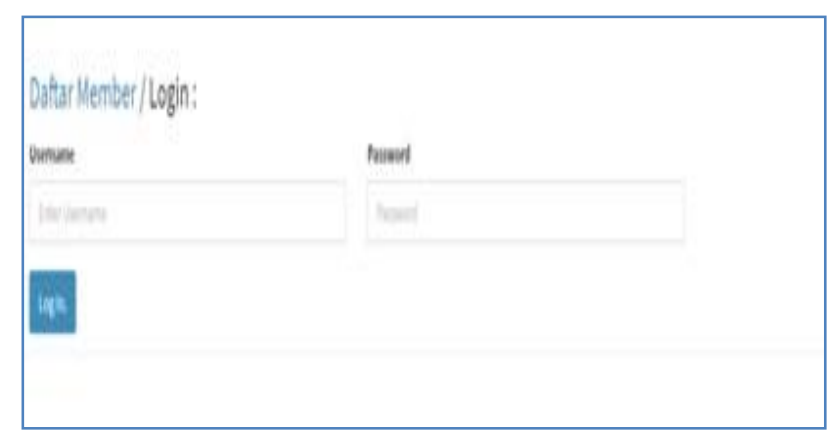

Gambar 4. Tampilan Menu Login

\section{E. Tampilan Menu Admin}

Tampilan menu admin merupakan merupakan tampilan dimana admin melakukan proses perubahan jadwal dokter, berita dan artikel.

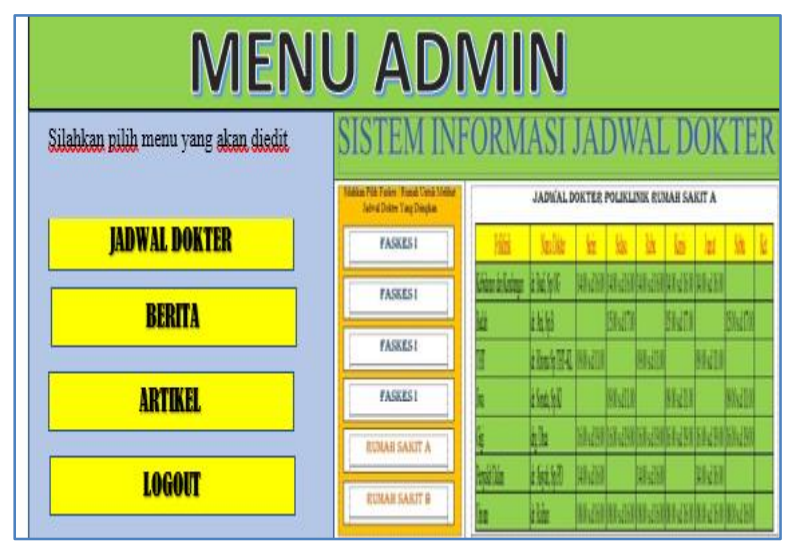

Gambar 5 Tampilan Menu Admin

\section{KESIMPULAN}

Berikut kesimpulan dari penelitian ini adalah sebagai berikut ;

Sistem informasi ini dapat digunakan dengan baik yang bertujuan untuk mempermudah calon pasien ata calon keluarga pasien untuk melihat jadwal dokter yang tersedia di setiap Faskes atau pun di Rumah Sakit. Codeigniter dapat mempermudah dalam proses pembuatan sistem informasi

Berdasarkan uraian diatas ada beberapa saran untuk sistem informasi jadwal dokter yaitu:

Agar aplikasi ini dapat diimplementasikan ke Faskes dan RUmah Sakit yang ada di Bengkulu

Aplikasi ini dapat dikembangkan lagi sehingga menu yang ditampilkan bisa lebih lengkap

\section{DAFTAR PUSTAKA}

[1].Romney, Marshal B, Paul John Steinbert., 2015.Accounting Information Systems, Salemba Empat, Jakarta.

[2]. Ladjamuddin, Al-bahra Bin., 2005. Analisis dan desain informasi.Yogyakarta: Graha ilmu.

[3].Mara Destiningrum, Qadhli Jafar Adrian.,2017.Sistem Informasi Penjadwalan Dokter Berbassis Web

[4].Dengan Menggunakan Framework Codeigniter (Studi Kasus: Rumah Sakit Yukum Medical Centre) 
[5].Jogiyanto, H.M., 2005. Analisis dan Desain Sistem Informasi, Andi Offiset, Yogyakarta.

[6].Nugroho, Adi., 2005. Rational Rose untuk Pemodelan Berorientasi Objek, Bandung

[7].Salim, Rin Rin Melani, 2013. Pengembangan Sistem Informasi Klinik Berbasis Web. Program studi S1 Sistem Informasi STMIK Microskil 